\title{
The Air Solar Collectors: Introduction of Chicanes to Favour the Heat Transfer and Temperature in the Air Stream Dynamics
}

\author{
Omar Mahfoud $^{1,2}$ a, Abdelhafid Moummi ${ }^{2,3}$, Noureddine Moummi ${ }^{2}$ \\ ${ }^{1}$ Centre de Développement des Énergies Renouvelables, CDER, BP 62, Route de l'Observatoire Bouzaréah, 16340, Algiers, Algeria \\ ${ }^{2}$ Laboratoire de Génie Mécanique, Université Mohamed Khider, BP 145, RP 07000, Biskra, Algeria \\ ${ }^{3}$ Laboratoire de Génie Civil, Hydraulique, Développement Durable et Environnement (LAR-GHYDE), Université Mohamed Khider, BP 145, \\ RP 07000, Biskra, Algeria
}

\begin{abstract}
The thermal performance of a single pass solar air heater with chicanes attached was investigated numerically using a 2D model of solar air stream dynamics collectors where the turbulence standard $(\mathbf{k}-\boldsymbol{\varepsilon})$ model has been implemented. The chicane is formed with two parts: the first is perpendicular to the air flow and the second part is titled $(\alpha)$, they are mounted in successive rows, oriented perpendicular to the air flow and soldered to the back plate. The predicted results are validated by comparing with the literatures semi-empirical and experimental data and shown a reasonable agreement. Effects of relevant parameters as the (Reynolds number, chicanes upper parts tilts angles and air mass flow rates) on the heat transfer coefficient and temperature development are discussed. It is apparent that the turbulence created by the chicanes resulting in greater increase in heat transfer inside the air stream dynamics.
\end{abstract}

\section{Introduction}

A solar air collector is simple in design and requires little maintenance. However, the value of the heat transfer coefficient between the absorber plate and air is low and these results in a lower efficiency, Yadav et al. [1].

To make the solar air heaters economically viable, their thermal efficiency needs to be improved by enhancing the heat transfer coefficient, which can be achieved by creating a fully turbulent flow in these systems and minimizing the heat loss with appropriate pressure drop and other factors. There are different factors have been developed in literatures (Dipprey and Sabersky [2], Menasria et al. [3], Moummi et al. [4]). The presence of laminar sub-layer between the absorber plate and flowing air is generally considered to be the main cause of thermal resistance for heat transfer. Artificially roughened absorber plate is considered to be a good methodology to break laminar sub-layer in order to reduce thermal resistance and to increase heat transfer, Prasad and Saini [5].

General arrangement of different types of roughness geometries reported by various investigators, they studied heat transfer enhancement and friction loss by fixing protruding wires of different shapes, size and orientations as an artificial roughness element on absorber plate as in Sahu and Bhagoria [6], Karmare and Tikekar [7].

The fast development of computational tools permits the prediction of heat, mass and momentum transfer and optimal design in various heat transfer and fluid flow processes using computational fluid dynamics simulation which is considered an effective tool for predicting the behaviour and performance of a solar air collector.

Literature reviews show that there has been less attention to the dynamic and the hydrodynamics flow behaviour around artificial roughness modelling by means of computational fluid dynamic simulations.

This study fits into the topic of "flow control" by an active technique in order to analysis the heat transfer in action, focusing particularly on the description of the temperature response to chicanes. It is, in short, to understand the mechanisms involved through the nature of heat transfer phenomena inside the air stream dynamics for different Reynolds number range, different range of chicanes tilted angle and different air mass flow rates.

\section{Flow configurations and mathematical foundation}

\subsection{Chicane geometry and arrangement}

Based on solar air flat plate collector usually used at the Mechanical Engineering Research Laboratory 'LGM' Biskra University, the physical model investigated in this work is presented in Fig. 1(a). The system of interest is horizontal square channel (air stream dynamics) with 13 chicanes placed on bottom channel walls in successive rows arrangements as shown in Fig. 1(a).

\footnotetext{
${ }^{\mathrm{a} C o r r e s p o n d i n g ~ a u t h o r: ~ o m a r c o n j @ y a h o o . f r, ~ o . m a h f o u d @ c d e r . d z ~}$
} 
For the flow module, the air enters the air stream dynamics at inlet temperature, $\mathrm{T}_{\mathrm{i}}=300 \mathrm{~K}$ and flows over obstacles where $\mathrm{h}_{1}, \mathrm{~h}_{2}$ and $\mathrm{e}$ and $\mathrm{b}$ are the obstacle orthogonal height, tilted $(\alpha)$ part height, full chicane height and thickness, respectively with: $\mathrm{h}_{1}=10 \mathrm{~mm}, \mathrm{~h}_{2}=$ $15 \mathrm{~mm}, \mathrm{e}=17.5 \mathrm{~mm}$ and $\mathrm{b}=0.4 \mathrm{~mm}$ while the thin obstacle is set to $\mathrm{e} / \mathrm{D}_{\mathrm{h}}=0.35$. The air stream dynamics height, $\mathrm{H}$ is $25 \mathrm{~mm}$. The hydraulic diameter is $\mathrm{D}_{\mathrm{h}} \approx 2 \mathrm{H}$. The axial pitch or spacing between the chicanes is set to $\mathrm{p}$ $=100 \mathrm{~mm}$ in which $\mathrm{p} / \mathrm{D}_{\mathrm{h}}=2$ is defined as the chicanes pitch ratio.

(a)

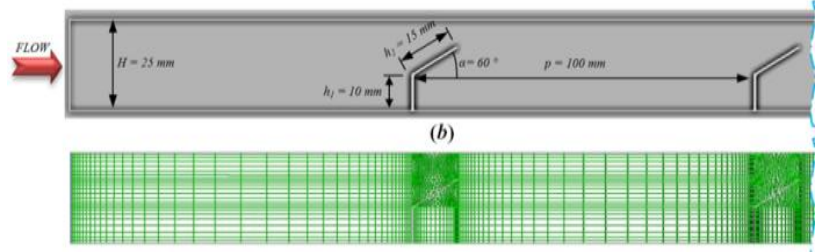

Figure 1. Model geometry; (a) Chicane dimensions (b) grid.

\subsection{Mathematical Modelling}

To build numerical models sufficiently detailed and accurate, it must sometimes take account of some assumptions.

The Reynolds averaged Navier-Stokes (RANS) equations and the energy equations govern the transport of the averaged flow quantities in the air stream dynamics, [8]. They can be written in Cartesian tensor form as: Continuity equation:

$\frac{\partial}{\partial x_{i}}\left(u_{i}\right)=0$

Momentum equation:

$\frac{\partial}{\partial x_{j}}\left(u_{i} u_{j}\right)=-\frac{1}{\rho} \frac{\partial P}{\partial x_{i}}+\frac{\partial}{\partial x_{j}}\left[\frac{\mu}{\rho}\left(\frac{\partial u_{i}}{\partial x_{j}}-\rho \overrightarrow{u_{i}^{\prime} u_{j}}\right)\right]$

The variable $\rho$ is the fluid density, and $u_{i}$ is a mean component of velocity in the direction $x_{i}, \mu$ is the dynamic viscosity, $P$ is the pressure, and $u^{\prime}$ is a fluctuating component of velocity. Repeated indices indicate summation from one to two by assuming towdimensional problems.

Energy equation:

$\frac{\partial}{\partial x_{j}}\left(u_{i} T\right)=\frac{\partial}{\partial x_{i}}\left(a \frac{\partial T}{\partial x_{j}}\right)$

Where $a$ is given by $a=\frac{\lambda}{\rho C_{p}}$ :

The Reynolds-averaged approach to turbulence modelling requires that the Reynolds stresses, $-\rho \overline{u_{i}^{\prime} u_{j}^{\prime}}$ must be modeled in order to close the equation (2) Help Fluent [8], Lunder et al. [9]. In this paper ,the Boussinesq hypothesis are employed to relate the Reynolds stresses to the mean velocity gradients with the same shape as a viscid stress tensor, i.e. that the turbulent flow behaves as a fluid of viscosity $\mu_{t}$ as seen in the equation below:

$-\rho \overrightarrow{u_{i}^{\prime} u_{j}^{\prime}}=\mu_{t}\left(\frac{\partial u_{i}}{\partial x_{j}}+\frac{\partial u_{j}}{\partial x_{i}}\right)-\frac{2}{3} \rho k \delta_{i j}$

Where $k$ is the turbulent kinetic energy as defined $k=\frac{1}{2} \overrightarrow{u_{i}^{\prime} u_{i}}$ and $\delta_{i j}$ is the Kronecker delta. An advantage of Boussinesq approach is the relatively low computational cost associated with the computation of the turbulent viscosity; $\mu_{t}$ depends on the close equation models. In Fluent, the Standard $(k-\varepsilon)$ model is the most widely used because of its robustness and is therefore valid only for fully turbulent flows, precision and relatively its low cost in computation time. This model is an example of two-equation models; turbulent kinetic energy and dissipation rate are obtained from the following equations, Mahfoud et al. [10].

$\frac{\partial}{\partial \mathrm{x}_{\mathrm{i}}}\left(\rho \mathrm{ku}_{\mathrm{i}}\right)=\frac{\partial}{\partial \mathrm{x}_{\mathrm{j}}}\left[\left(\mu+\frac{\mu_{\mathrm{t}}}{\sigma_{\mathrm{k}}}\right) \frac{\partial \mathrm{k}}{\partial \mathrm{x}_{\mathrm{j}}}\right]+\mathrm{G}_{\mathrm{k}}+\mathrm{G}_{\mathrm{b}}-\rho \varepsilon$

$\frac{\partial}{\partial x_{i}}\left(\rho \varepsilon u_{i}\right)=\frac{\partial}{\partial x_{j}}\left[\left(\mu+\frac{\mu_{t}}{\sigma_{\varepsilon}}\right) \frac{\partial \varepsilon}{\partial x_{j}}\right]+C_{\varepsilon 1} \frac{\varepsilon}{k}\left(G_{k}+C_{\varepsilon 3} G_{b}\right)-$

$\mathrm{C}_{\varepsilon 2} \rho \frac{\varepsilon^{2}}{\mathrm{k}}$

The term $G_{k}$, representing the production of the turbulence kinetic energy due to the average velocity gradient. From the exact equation for the transport of $k$, this term may be defined as:

$G_{k}=-\overline{u_{i}^{\prime} u_{i}^{\prime}} \frac{\partial u_{j}}{\partial x_{i}}$

To evaluate $G_{k}$ in a manner consistent with Boussinesq hypothesis;

$G_{k}=\mu_{t} S^{2}$

With $S=\sqrt{2 S_{i j} S_{i j}}$ where $S$ is the modulus of mean rateof-strain tensor: $S_{i j}=\frac{1}{2}\left\{\frac{\partial u_{i}}{\partial x_{j}}+\frac{\partial u_{j}}{\partial x_{i}}\right\}$

And $G_{b}$ is the generation of the turbulence kinetic energy due to the buoyancy.

In the above equations $C_{\varepsilon 1}, C_{\varepsilon 2}$ and $C_{\varepsilon 3}$ are constants. $\sigma_{k}$ and $\sigma_{\varepsilon}$ are the turbulent Prandtl numbers for $k$ and $\varepsilon$, respectively. The effective viscosity $\mu_{t}$ is written by; $\mu_{t}=\rho C_{\mu} k^{2} / \varepsilon$

The model constants have the following values: $C_{\varepsilon 1}=1.44, C_{\varepsilon 2}=1.92, C_{\mu}=0.09, \sigma_{k}=1.0, \sigma_{\varepsilon}=1.3$.

There are different parameters of interest in the present work, namely, the Reynolds number and the convective heat transfer factor. The Reynolds number is defined as:

$R e=\rho u_{i} D_{h} / \mu=2 \dot{m} / \mu$

Where $\mu$ is the dynamic viscosity and $D_{h}$ is the hydraulic diameter of the air stream dynamics, defined as:

$D_{h}=4 A_{f} / P_{w} \approx 2 H$

Where $A_{f}$ is the mean cross sectional area and $P_{w}$ is the wetted perimeter of the cross-section.

Steady-state values of the plate and air temperatures in the air stream dynamics at various locations were used to determine the values of useful parameters, that is the heat furnished to the air ' $Q_{\mathrm{u}}$ ' and heat transfer coefficient ' $h$ ' calculated as:

$h_{c}=\frac{Q_{u}}{A_{p}\left(T_{a}-T_{f}\right)}$

$Q_{u}=\dot{m} C_{p}\left(T_{o}-T_{i}\right)$

Where the mean air temperature $T_{f}=\left(T_{o}-T_{i}\right) / 2$ and $T_{o}, T_{i}$ and $T_{a}$ are respectively the outlet air temperature, inlet air temperature and absorber temperature.

\section{Results and discussion}

\subsection{Thermal aspects}




\subsubsection{Reynolds number effect on the heat transfer coefficient}

The results presented on Fig. 2, show the Reynolds number variation effect on the convection heat transfer coefficient $\left(h_{c}\right)$ between the absorber plate and air. It's clear that are in good agreement with Semi-empirical relationship and experimental results Menasria et al. [3]. It is seen that at laminar flow $(R e \leq 2100)$, the heat transfer coefficient vary gradually in the range of (4 to 31 $\left.W / m^{2} K\right)$, therefore the turbulent flow $(\operatorname{Re} \geq 2100)$, the increase in heat transfer coefficient begins to be perceived ( 31 to $73 \mathrm{~W} / \mathrm{m}^{2} \mathrm{~K}$ ). By comparison to the case without chicane (smooth air stream dynamics), the average heat transfer coefficient is accompanied by a rise of $23 \%$.

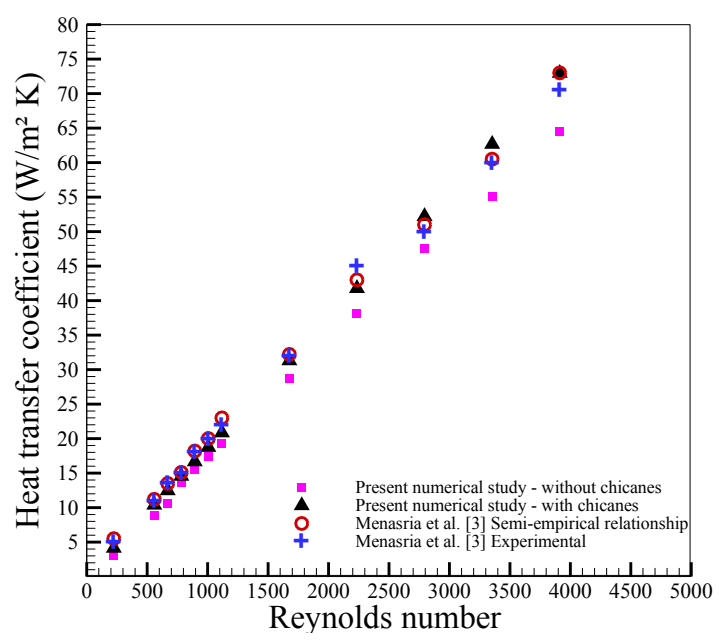

Figure 2. Heat transfer coefficient Vs. Reynolds number.

\subsubsection{Upper parts angles effect on the static temperature}

Fig. 3 shows that the use of chicanes as artificial roughness influence significantly on the temperature field, as noted by Aoues et al. [11], Mahboub et al. [12]. For mass flow rate of $0.035 \mathrm{~kg} / \mathrm{s}$, it is observed that the air temperature increasing along the air stream dynamics length with a mean of $(316.3 \mathrm{~K})$ in the smooth case and with an average of $(324.3 \mathrm{~K}, 329.5 \mathrm{~K}, 330.7 \mathrm{~K}$ and 332.1 $K$ ) in the case (without inclined part, $0^{\circ}, 45^{\circ}$ and $60^{\circ}$ ) with a rise of $(2.52 \%, 4.17 \%, 4.55 \%$ and $4.99 \%$ )respectively. This is due to the secondary flow when it is trapped between two chicanes and the main flow where powered with a brewing phenomenon which provokes a heat transfer from the hot flow to the cold one, therefore the chicanes provide a delaying aspect for more and more time to the heat transfer process which is confirmed by Moummi et al. [4-13].

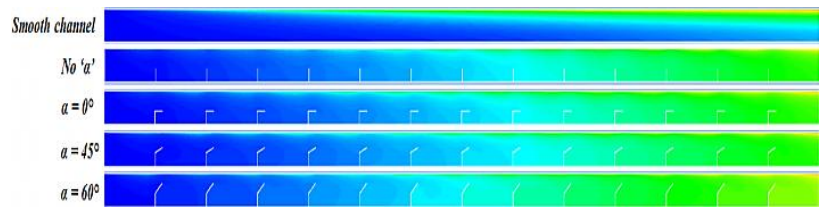

Figure 3. Temperature contours.

\subsection{Quantitative aspects}

Different parameters profiles are plotted such as the temperature in several abscissas sections along the air stream dynamics were $\left(\alpha=60^{\circ}\right)$, Fig. 4 .

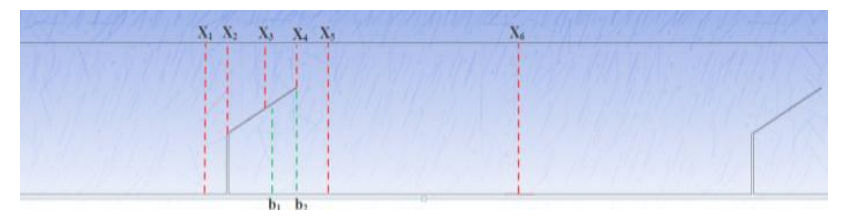

Figure 4. Cross sections positions relative to the chicanes.

\subsubsection{Air mass flow rates effect on the temperature evolution}

Fig. 5 shows the temperature evolution across the air stream dynamics height, just on the downstream and upstream of the chicanes obtained from CFD analysis. The temperature profiles are plotted in several abscissas sections on the axial positions; $\mathrm{X}_{1}=0.08 \mathrm{~m}, \mathrm{X}_{2}=0.1 \mathrm{~m}$, $\mathrm{X}_{3}=0.107 \mathrm{~m} . \mathrm{X}_{4}=0.1134 \mathrm{~m}, \mathrm{X}_{5}=0.1154 \mathrm{~m}, \mathrm{X}_{6}=0.15$ $\mathrm{m}, \mathrm{b}_{1}=0.1072 \mathrm{~m}, \mathrm{~b}_{2}=0.1134 \mathrm{~m}$.It is observed in general, that the air mass flow rate has a great influence on the temperature, the latter increases when the air mass flow rate decreases. From $\mathrm{X}_{1}$ to $\mathrm{X}_{4}$ position, the profile is identical were the temperature increases with air stream dynamics height. At $\mathrm{X}_{5}$ position to $\mathrm{X}_{6}$, at downstream of the chicane, temperature value changes and increases compared to the value at the upstream position of the chicane. The positions $\left(b_{1}, b_{2}\right)$ located downstream and below the chicane tilted part, at these locations the temperature remains almost constant.By conclusion, the use of chicanes is for creating turbulence which increases the temperature; this is inversely proportional to the air mass flow rate.

\section{Conclusions}

In this article a CFD investigation is also carried out to select heat transfer process in air solar collectors having roughened plate provided with artificial roughness (chicanes) with tilted upper parts has been made to carry out numerically as an illustrative example of the twodimensional use in CFD. A two-dimensional flow is assumed. The influences of the relevant parameters as the (Reynolds number, chicanes tilts angle and air mass flow rates) on heat transfer coefficient and temperature development are discussed, the analysis of the obtained numerical solutions which has a good agreement with literatures.

The presence of the chicanes in solar air collectors create turbulent air flow, provides a delaying aspect, enrich the maximal extraction of the absorber energy, involve better air mixing and to stimulate heat transfer which has a rise of $23 \%$ compared with the smooth case. The arrangement of the artificial roughness (chicane) has an important influence on the flow development. The angles of the upper parts $(\alpha)$ are demonstrated to significantly affect the air flow and heat transfer rate. Increasing the angles $(\alpha)$ can make the heat transfer 
performance become better and increase significantly the average temperature.

The temperature decrease by increasing air mass flow rates from $0.005 \mathrm{~kg} / \mathrm{s}$ to $0.02 \mathrm{~kg} / \mathrm{s}$.
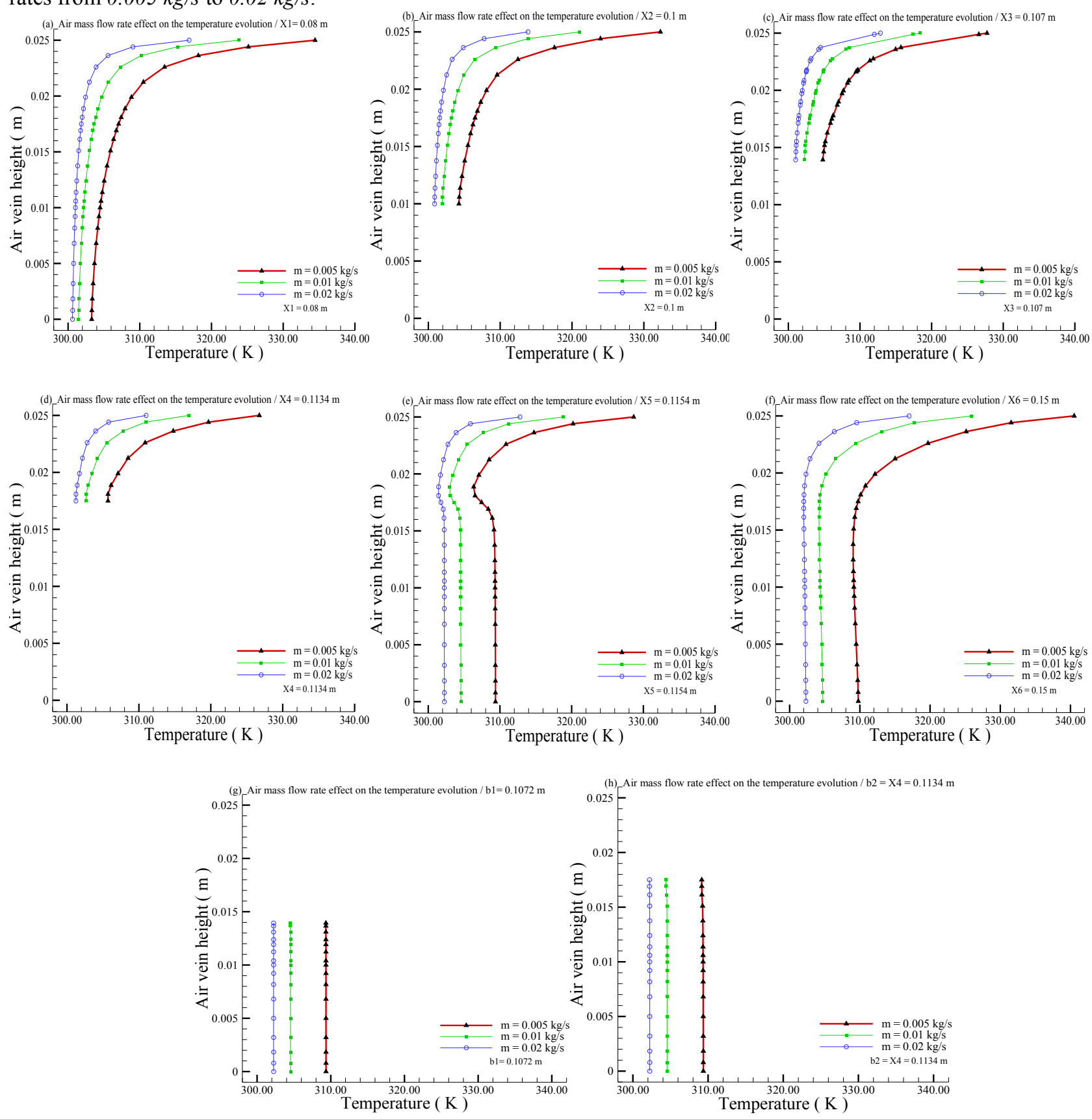

Figure 5. Air mass flow rates effect on the temperature evolution at different axial locations.

\section{References}

1. A.S. Yadav, J.L Bhagoria, Renew. Sustainable Energy Rev., 23 (2013)

2. D.P. Dipprey, R.H. Sabersky, Int J of Heat and mass Tran, 6 (1963)

3. F. Menasria, et al., Revue des Energies Renouvelables 14, 3 (2011)

4. N. Moummi, S.Y. Ali, A. Moummi and J.Y. Desmons, Renew. Energy 29 (2004)

5. B.N. Prasad, J.S. Saini, Solar Energy 41 (1988)
6. M.M. Sahu, J.L. Bhagoria, Renew. Energy 30 (2005)

7. S.V. Karmare, A.N. Tikekar, Int J Heat Mass Tran 50 (2007)

8. Help Fluent Documentations Inc 2006

9. B.E. Launder, D.B. Spalding, Lectures in Mathematical Models of Turbulence, Academic Press: England, (1972)

10. O. Mahfoud et al., International Journal of Sustainable Energy 34,2 (2015)

11. K. Aoues et al., International Journal of Ambient Energy 32 (2011)

12. C. Mahboub, N. Moummi, Solar Energy 86 (2012) 
ICAME 2015

13. N. Moummi, A. Moummi, K. Aoues, C. Mahboub, and S. Youcef-Ali, International Journal of Sustainable Energy 29 (2010) 